\title{
WIRELESS COMMUNICATIONS BEYOND 5G: UNCERTAINTIES OF TERAHERTZ WAVE ATTENUATION DUE TO RAIN
}

\author{
M. Tamošiūnaitè ${ }^{a}$, V. Tamošiūnas ${ }^{a, b}$, and G. Valušis ${ }^{a}$ \\ ${ }^{a}$ Center for Physical Sciences and Technology, Sauletekio 3, 10257 Vilnius, Lithuania \\ ${ }^{\mathrm{b}}$ Institute of Photonics and Nanotechnology, Vilnius University, Sauletekio 3, 10257 Vilnius, Lithuania \\ Email: milda.tamosiunaite@ftmc.lt
}

Received 17 April 2018; revised 15 May 2018; accepted 21 June 2018

\begin{abstract}
Statistical peculiarities of terahertz $(\mathrm{THz})$ wave attenuation in heavy rain conditions are evaluated. The expected extreme densification of the infrastructure and the application of highly directional beams of 5th generation $(5 \mathrm{G})$ and beyond 5G (B5G) wireless networks were taken into account. Calculations were performed emulating both drop size distributions of the real rain and the laboratory-controlled rain described in literature. Simulation results revealed that absorbance fluctuations of more than one percent would occur if $\mathrm{THz}$ waves and raindrops interact within the $100 \mathrm{~m}^{3}$ volume. For much smaller volumes, short distances and narrow beams used for experiments with the laboratory-controlled rain, absorbance uncertainties could exceed the average absorbance value. A comparison of the simulation results at fixed average absorbance revealed that slightly lower uncertainties were expected in the case of a single raindrop size when compared to the Weibull distribution approximating the real rain. Nevertheless, in both cases the predicted deviations were substantially smaller than observed in the previously published experimental results. This fact predicts a new future application possibility for such laboratory-based experiments - they can be employed to predict the performance of wireless THz data transmission links when the resilience margin is required. Since much of the existing industrial test equipment is not designed to carry out calibrated over-the-air measurements of $5 \mathrm{G} / \mathrm{B} 5 \mathrm{G}$ wireless networks, such experiments can be employed to primarily predict the performance of data transmission links.
\end{abstract}

Keywords: terahertz, rain, attenuation, wireless communications, Mie scattering

PACS: 92.40.Ea, 84.40.Ua, 42.25.Fx

\section{Introduction}

In recent years, the world mobile data traffic has been growing nearly exponentially (Fig. 1(a)) and this trend is expected to continue for at least several more years [1]. The delay-sensitive video traffic is one of the major contributors to this data stream today and is expected to become the major one in just several years from now (Fig. 1(c)). The available bandwidth $W$ is one of the factors limiting the data transmission rate $C$ (in bits/s) according to the classical formula proposed by Shannon [2]:

$$
C=W \log _{2}(1+P / N) \text {. }
$$

Here $P$ and $N$ are the average signal and noise powers, respectively.

This limit and allocation of frequency ranges to specific applications would severely restrict the future growth of wireless data communications unless new frequency ranges are exploited. Therefore, the availability of the unallocated bandwidth in sub-terahertz (sub-THz) and terahertz $(\mathrm{THz})$ ranges together with a fast development of system components has spurred a rapid research of $\mathrm{THz}$ applications in communications during recent years [3-8]. Wide up to $120 \mathrm{GHz}$ spectrum bands with a relatively low atmospheric absorption in tropical humidity conditions can be found in these 

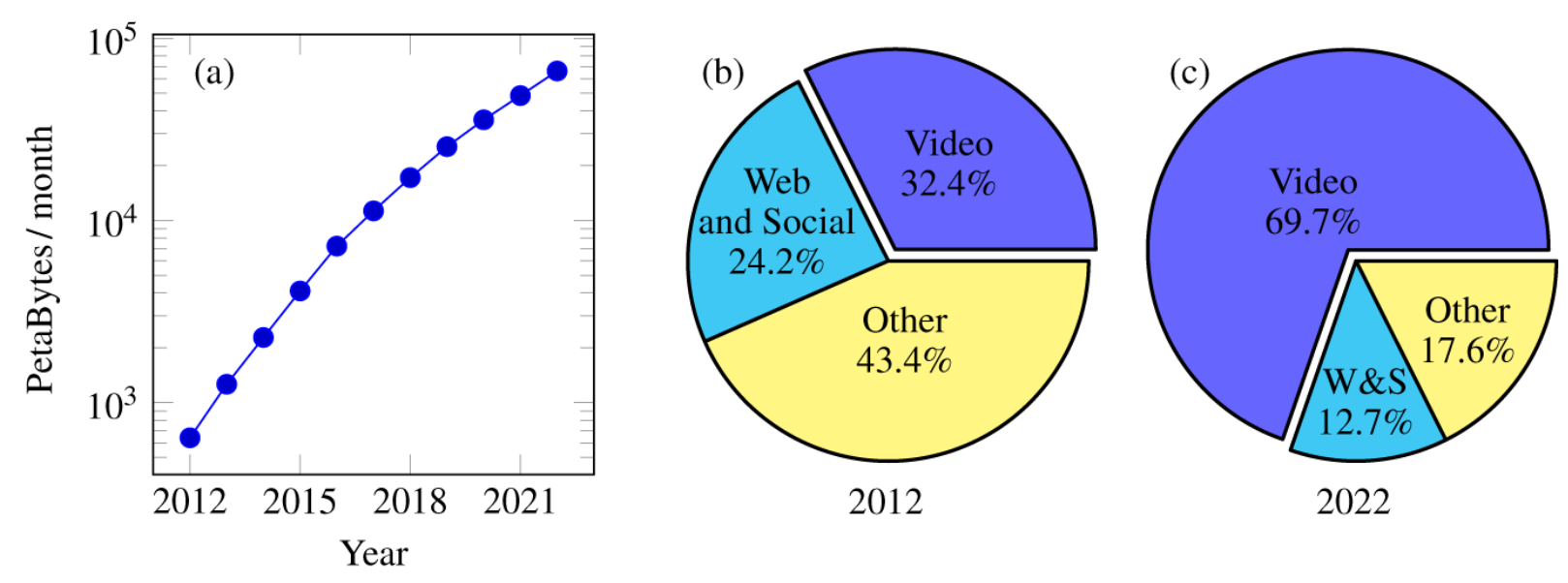

Fig. 1. World mobile data traffic (a), its distribution by an application type in 2012 (b) and the predicted one for 2022 (c) according to the data presented in [1]. W\&S denotes the combined traffic related to web browsing and social networking applications, while software downloads, updates, file sharing and audio data streams are grouped with the remaining other applications into the Other field.

ranges [8], but challenges due to free space losses, fog and rain have to be considered when evaluating the feasibility of $\mathrm{THz}$ communications at particular conditions.

The influence of free space losses for the wavelength $\lambda$ can be evaluated from the classical Friis radio link formula [9]

$$
P_{\mathrm{r}}=\frac{G_{\mathrm{t}} G_{\mathrm{r}} \lambda^{2}}{(4 \pi d)^{2}} P_{\mathrm{t}}
$$

where $P_{\mathrm{r}}$ and $P_{\mathrm{t}}$ are the received and transmitted power by receiving and transmitting antennas of $G_{\mathrm{r}}$ and $G_{\mathrm{t}}$ gains, respectively, at the distance $d$. For the fixed $P_{\mathrm{r}} / P_{\mathrm{t}}$ ratio, shorter wavelengths have to be compensated either by reduced distance $d$ or by increased gains $G_{\mathrm{t}}$ and $G_{\mathrm{r}}$ of antennas. This is one of the major reasons why large-scale antenna systems with beamforming [10] and multiple-input multiple-output (MIMO) communication signal processing techniques [11] are actively investigated for future millimetre wave 5th generation (5G) networks. However, the use of highly directional antennas might be nontrivial even at short ranges due to problems related to standing waves and misalignments of antennas in an extreme case of near-field $\mathrm{THz}$ communications [12].

The averaged attenuation of $\mathrm{THz}$ radiation due to atmospheric gasses and rain has also been investigated intensively during recent decades and detailed International Telecommunication Union (ITU) recommendations P.676-11 [13] and P.838-3 14 are available today for frequencies up to $1 \mathrm{THz}$. The Recommendation P.838-3 provides relatively simple means to calculate the power-law relationship between the rain rate and the specific attenuation. The challenging part of its application is evaluation of the rain rate value. In [15], the ITU models for the calculation of electromagnetic wave attenuation due to atmospheric humidity were revised using local data. It was concluded that due to the nature of heavy rain (high intensity, short duration), the averaged and actual rain rate values significantly mismatched. Therefore, meteorological data readings should be performed in a one-minute interim or conversion models should be applied. However, this simplified approach is only one of the available alternatives. For example, M. Sekine et al. [16] considered the Mie scattering theory for five raindrop-size distributions and determined that the Weibull distribution best describes the rain attenuation above $30 \mathrm{GHz}$. In a later work it was demonstrated that the Mie scattering theory with Best and P-S distributions provide the most suitable agreement with the experimental values in the $90-225 \mathrm{GHz}$ range, while the ITU-R model and Mie scattering with the Weibull distribution leads to a better approximation at 313 and $355 \mathrm{GHz}$ [17]. It could also be mentioned that both researches of the origins of raindrop size distributions [18] and search for the best empirical description of these distributions [19] continued well past the publication of the P.838-3 recommendation in 2005 and, 
therefore, alternative descriptions can and have to be discussed. The Weibull distribution will be considered further in our work in more detail, since it provides both the best percentage of the most successful approximations of raindrop-size distributions [19] and one of the most relevant $\mathrm{THz}$ attenuation approximations in [16] and [17].

The purpose of this paper is to theoretically examine in more detail the expected peculiarities of $\mathrm{THz}$ wave attenuation due to rain in the case of short-range communications with narrow beam high-gain antennas. As described above, such scenarios will most probably be necessary to provide high bit-rates with sub- $\mathrm{THz}$ and $\mathrm{THz}$ carrier frequencies. Narrow beams and relatively short distances would also reduce the volume in which the interaction between $\mathrm{THz}$ waves and raindroplets occurs. In turn, this might mean substantial deviations of instantaneous absorption from the well-known averaged attenuation models. To our knowledge, a detailed theoretical study of such 'shot-noise' has not been performed up to now. However, a substantial dispersion of values is visible in the experimental data presented in [16] and [17]. Furthermore, such dispersion can be seen even in the case of the laboratory-controlled rain at extreme $50-400 \mathrm{~mm} / \mathrm{h}$ rain rates with a relatively narrow Gaussian-like raindrop size distribution [20].

This paper is organized as follows. Section 2 describes the simulation methods and consists of two parts. In the first part, the averaged scattering and absorption by raindrops is briefly described in terms of the classical scattering theory. In the second part, two data transmission scenarios are considered. Then, Section 3 provides the calculation results and a comprehensive analysis of both scenarios. Finally, the conclusions are presented in Section 4.

\section{Simulation methods}

\subsection{Averaged scattering and absorption by raindrops}

The classical scattering theory for plane wave radiation by absorbing sphere particles [21] is a widely used (including [4, 16, 17, 20]) tool for a detailed analysis of the absorption in the $\mathrm{THz}$ range and also serves as a starting point for our calculations. The rain attenuation coefficient $\alpha$ within this theory is calculated as

$$
\begin{aligned}
& \alpha=4.343 \int_{0}^{\infty} N(D) Q_{\mathrm{t}}(D, \lambda, m) \mathrm{d} D \\
& Q_{\mathrm{t}}(D, \lambda, m)=\frac{\lambda^{2}}{2 \pi} \sum_{n=1}^{\infty}(2 n+1) \operatorname{Re}\left[a_{n}+b_{n}\right]
\end{aligned}
$$

where $D$ is the raindrop diameter, $N(D)$ is the raindrop size distribution, $Q_{t}(D, \lambda, m)$ is the attenuation cross-section of a raindrop, $\lambda$ is the wavelength, $m$ is the complex coefficient of refraction for water, $a_{n}$ and $b_{n}$ are the Mie scattering coefficients, and the 4.343 factor is used to obtain values in $\mathrm{dB}$ per unit distance (for example, $\mathrm{dB} / \mathrm{km}$ from $1 / \mathrm{km}$ ). Values of $m$ in sub-THz and $\mathrm{THz}$ ranges were taken from [22] and we used Matlab functions from [23] to compute the Mie scattering coefficients. The Weibull distribution and coefficients from [16, 17] were used to evaluate $N(D)$ :

$$
N(D)=N_{0} \frac{c}{b}\left(\frac{D}{b}\right)^{c-1} \mathrm{e}^{-(D / b)^{c}} .
$$

Here $N_{0}=1000 \mathrm{~m}^{-3}, b=0.26 R^{0.44} \mathrm{~mm}, c=0.95 R^{0.14}$ and $R$ is the rain rate in $\mathrm{mm} / \mathrm{h}$.

\subsection{Data transmission scenarios}

Two data transmission scenarios will be discussed for a step-by-step theoretical analysis in this paper.

Scenario 1. The first baseline one is a case of large antennas or their arrays, a relatively large (in the context of sub- $\mathrm{THz}$ and $\mathrm{THz}$ transmission) distance, a quasi-optical transmission and a uniform beam shape between the antennas. This scenario is expected to provide the smallest deviations from the averaged loss models used in [14. 16, 17, 20, due to a large interaction volume between the sub- $\mathrm{THz}$ waves and raindrops. At $L=100 \mathrm{~m}$ distance and $\lambda \approx 1 \mathrm{~mm}$ wavelength, approximately the $d_{\mathrm{a}}=1 \mathrm{~m}$ diameter of a parabolic reflector or an antenna array would be required to maintain the $\lambda / d_{\mathrm{a}} \approx 0.1 \times \mathrm{d}_{\mathrm{a}} / L$ ratio and to prevent a substantial beam divergence. For more compact solutions, either short distances or diverging beams have to be considered.

Scenario 2. The quasi-optical transmission with a narrow beam at short distances is a second 
scenario. The average number of raindrops would be reduced substantially in such scenario due to a small interaction volume. $L=4 \mathrm{~m}$ and $d_{\text {eff }}=2 \mathrm{~cm}$ effective average beam diameter were selected in this scenario for an easier comparison of the results with the experimental data in the case of the controlled rain in laboratory conditions [20].

\section{Calculation results}

Distributions of the raindrop sizes obtained from Eq. (5) are presented in Fig. 2(a) for several rates of heavy rain. Temperature of $t=20^{\circ} \mathrm{C}$ and $f=0.3 \mathrm{THz}$ frequency were specified when calculating the complex coefficient of refraction of water and attenuation cross-sections (also presented in Fig. 2(a)) of water drops. Contributions by raindrops of various sizes to the rain attenuation coefficient (Eq. (3)) are shown in Fig. 2(b). Several features are immediately visible when examining the data presented in both panels of this figure. First, small raindrop cross-section areas $S=\pi \cdot D 2 / 4$ and low $Q_{\mathrm{t}} / S$ ratios lead to low contributions to the overall loss by drops with $D<0.2 \mathrm{~mm}$ even at the lowest rain rate of $R=10 \mathrm{~mm} / \mathrm{h}$ with the highest concentrations of small drops. For higher rain rates, larger drops of $D>0.2 \mathrm{~mm}$ start to dominate both in terms of concentrations (Fig. 2(a)) and contributions to the overall loss. Maxima in Fig. 2(b) are shifted to higher $D$ values with respect to Fig. 2(a) due to a fairly constant $Q_{t} / S$ ratio for higher $D$ values and thus a higher contribution

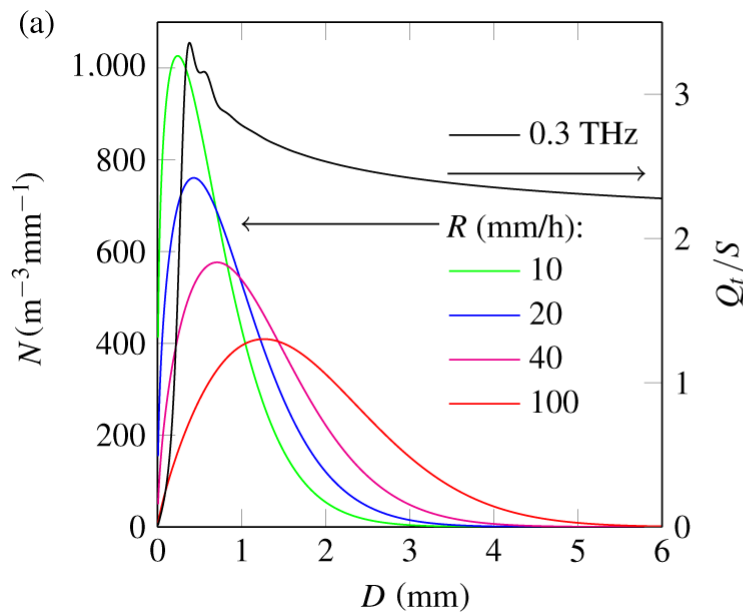

of larger drops. At the $R \geq 40 \mathrm{~mm} / \mathrm{h}$ rate, a large contribution of drops with the $D>3 \mathrm{~mm}$ diameter is predicted. This fact places a practical upper limit for such analytical model application, because substantially lower $N(D)$ experimental values than predicted by Weibull distribution were reported previously around $D \approx 3 \mathrm{~mm}$ for 43.25 and $46.40 \mathrm{~mm} / \mathrm{h}$ rates [16]. Although this issue can be avoided in experiments with the laboratorycontrolled rain, in which both narrow distributions around $\bar{D}=1.9 \mathrm{~mm}$ and rates of $R>400 \mathrm{~mm} / \mathrm{h}$ can be achieved [20], but we focus on a close to naturally occurring distribution in our paper.

Several initial estimations can be made for the base Scenario 1 in which wave interaction with raindrops within a large volume of $V \approx 100 \mathrm{~m}^{3}$ order and independently appearing raindrops is assumed. Even for narrow ranges of raindrop diameters $\Delta D=0.01 \mathrm{~mm}$, the average number of raindrops in such size intervals would reach tens and hundreds for most sizes of interest. In such conditions, the Poisson distribution, which is appropriate for the number of independent raindrops within the given interval of sizes, could be approximated by normal distribution with the probability density function

$$
f\left(n_{i}\right)=\frac{1}{\sqrt{2 \pi \sigma^{2}}} \mathrm{e}^{-\frac{\left(n_{i}-\mu\right)^{2}}{2 \sigma^{2}}},
$$

where $n_{i}$ is the number of interacting with the wave raindrops with sizes between $D_{i}-0.5 \Delta D$ and

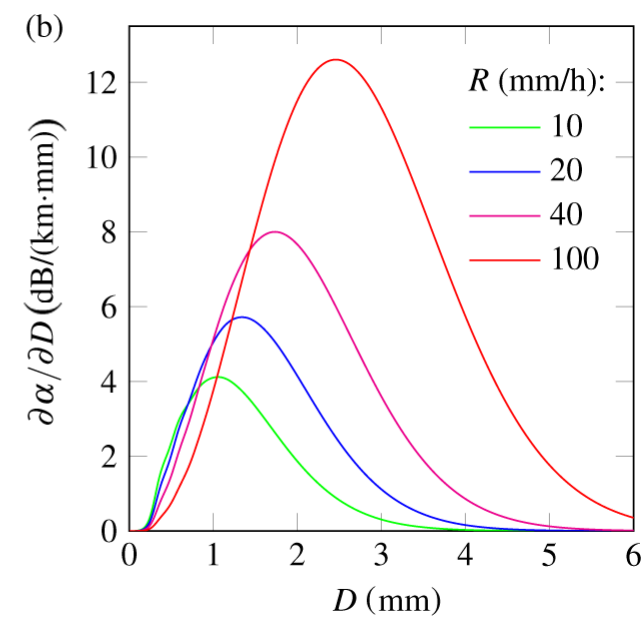

Fig. 2. (a) Distributions of raindrop sizes for several rain rates $R$; the dependence of $Q_{t}$ and the raindrop cross-section area $S=\pi \cdot D 2 / 4$ ratio on the diameter of the raindrop for $f=0.3 \mathrm{THz}$ frequency. (b) Dependence of the contribution to the averaged absorption coefficient on the diameter of the raindrop at $f=0.3 \mathrm{THz}$ for several rain rates $R$. 
$D_{i}+0.5 \Delta D, D_{i}$ is the average drop diameter in the $i$ th range, $V$ is the volume in which interaction between the wave and raindrops occurs, and $\mu=\sigma^{2}=N\left(D_{i}\right) V \Delta D$ (mean number of drops in this range and volume, variance).

Loss $\alpha_{i}$ induced by raindrops in the $i$ th interval can be evaluated using Eq. (3) and multiplication by $\Delta D$ can replace the integration for small $\Delta D$,

$$
\alpha_{i} \approx 4.343 n_{i} Q_{\mathrm{t}}\left(D_{i}, \lambda, m\right) / V
$$

and thus $\alpha_{i}$ is also normally distributed with the mean of (in $\mathrm{dB} / \mathrm{km}$ units)

$$
\bar{\alpha}_{i}=4.343 N\left(D_{i}\right) Q_{t}\left(D_{i}, \lambda, m\right) \Delta D,
$$

and the variance of

$$
\begin{array}{r}
\sigma_{i}^{2}=\left(4.343 Q_{\mathrm{t}}\left(D_{\mathrm{i}}, \lambda, m\right)\right)^{2} N\left(D_{i}\right) \Delta D / V= \\
=\frac{\bar{\alpha}_{i}^{2}}{N\left(D_{i}\right) V \Delta D} .
\end{array}
$$

Within the model of independent raindrops, the absorption coefficient $\alpha_{\mathrm{r}}$ for wider ranges between $i_{1}$ and $i_{2}$ can be expressed as

$$
\alpha_{\mathrm{r}}=\sum_{i=i_{1}}^{i_{2}} \alpha_{i}, \quad \bar{\alpha}_{\mathrm{r}}=\sum_{i=i_{1}}^{i_{2}} \bar{\alpha}_{i}, \quad \sigma_{\mathrm{r}}^{2}=\sum_{i=i_{1}}^{i_{2}} \sigma_{i}^{2} .
$$

The results of such calculations for several rain rates are presented in Table 1 . The triple $\sigma_{\mathrm{r}}$ value is presented for an easy estimation of the limit in which nearly all $(99.7 \%) \alpha_{\mathrm{r}}$ values fit. Three drop diameter ranges (tentatively could be described as small, medium and large drops) were selected for each $R$ to provide approximately equal $\bar{\alpha}_{\mathrm{r}}$ values. At $V=100 \mathrm{~m}^{3}$ volume, $3 \sigma_{\mathrm{r}}$ exceeds $1 \%$ of the mean value of the absorption coefficient for the entire range of sizes between $D_{1}=0$ and $D_{2}=6 \mathrm{~mm}$ in both cases. Contribution of the largest drops (with $D>1.57 \mathrm{~mm}$ and $D>1.9 \mathrm{~mm}$ diameters, respectively) to the deviation is dominating in both cases.

This result presents both additional possibilities and additional challenges. An average diameter of $\bar{D}=1.9 \mathrm{~mm}$ and a narrow distribution of sizes were obtained in experiments with the laboratory-controlled rain [20] and thus this experimental set-up and measurement data could also be used for statistical estimations of 'shot-noise' induced by large raindrops in addition to evaluation of the averaged absorption. However, the experimentally observed lower numbers of the largest raindrops than predicted by Weibull distribution [16] in the case of the real rain means that noise might be somewhat overestimated by this theoretical model and recalculation of results from laboratory-controlled rain experiments or theoretical calculations is not straightforward in all cases. Nevertheless, an explicit $\sigma_{i} \mu V^{-1 / 2}$ dependence in Eq. (9) means that one should expect $3 \sigma_{\mathrm{r}}$ uncertainties to grow into tens of percent of the average value once $V \approx 1 \mathrm{~m}^{3}$ beamrain interaction volumes are approached. This value is extremely low for today's wireless communications. For example, a distance between the user equipment and the base station would be limited to $\sim 100 \mathrm{~m}$ even for the $\sim 1 \mathrm{dm}^{2}$ average effective crosssection of a beam from a compact highly directional antenna, thus leading to densities of tens or hundreds base stations per $\mathrm{km}^{2}$. Such values, however, are exactly of the same order as ones discussed for ultradense outdoor 5G networks [24], and thus the influence of absorption coefficient deviations will have inevitably be considered for $5 \mathrm{G}$.

Table 1. Attenuation coefficients and their expected uncertainties at $f=0.3 \mathrm{THz}$ for $V=100 \mathrm{~m}^{3}$

\begin{tabular}{cccccc}
\hline$R, \mathrm{~mm} / \mathrm{h}$ & $D_{1}, \mathrm{~mm}$ & $D_{2}, \mathrm{~mm}$ & $\alpha_{\mathrm{r}}, \mathrm{dB} / \mathrm{km}$ & $3 \sigma_{\mathrm{r}}, \mathrm{dB} / \mathrm{km}$ \\
\hline 10 & 0 & 1.00 & 2.15 & 0.032 \\
\hline & 1.01 & 1.56 & 2.12 & 0.054 \\
\hline & 1.57 & 6.00 & 2.13 & 0.087 \\
\hline & 0 & 6.00 & 6.39 & 0.108 \\
\hline & 0 & 1.24 & 3.47 & 0.050 \\
\hline & 1.25 & 1.89 & 3.48 & 0.083 \\
\hline
\end{tabular}


The transition to Scenario 2 and the comparison with the experimental data of [20] brings additional challenges. A small $V \approx 1.26 \mathrm{l}$ volume and Fig. 2(a) data mean that the average number of raindrops interacting with the wave might be well below 1 for each $i$. Thus, the Poisson statistics was employed instead of a normal distribution approximation. In addition, influences of multiple measurement (1000 in [20]) averaging and the influence of more uniformly distributed drop sizes of the experimental setup have to be assessed.

The results of such emulated measurements representing 1000 numerically generated raindrop size distributions within the communication channel are presented in Fig. 3. For each emulated measurement, random numbers of drop size values were generated for each $i$ th size range according to the Poisson probability distribution. Afterwards, contributions of all drops were integrated to obtain the absorbance $A$ value for this particular raindrop size distribution. A histogram plot representing the number of emulated single 'measurements' $n_{\text {sim_val }}$ within the absorbance intervals of $0.007 \mathrm{~dB}$ are presented in Fig. 3. The average expected absorbance of $\alpha_{\mathrm{r}} \cdot L=0.069 \mathrm{~dB}$ based on Eq. (3) for this rain rate and a length of $L=4 \mathrm{~m}$ is indicated by an arrow in the same figure. As one can clearly see in this figure, several of such numerically generated raindrop sets would cause an approximately one order of magnitude larger absorbance than the expected average.

The average value of the simulated absorbance $\bar{A}$ and its standard deviation $\sigma_{A}$ were also calculated and are also indicated by lines in Fig. B(a). A slight difference between $\alpha_{\mathrm{r}} \cdot L$ and $\bar{A}$ can be noticed suggesting that 1000 sets of raindrops (or data points for averaging in the experiment) are still insufficient to obtain a precise value of the average absorbance. To verify this assumption, a simulated experiment was repeated 100 times (with 1000 measurements averaging in each) and the distribution of $\bar{A}$ is presented in Fig. 3(b). It confirms that indeed substantial deviations of the order of several percent (from the real average value) are still probable even with such seemingly large data set averaging.

The same numerical experiment series was repeated for the same $0.069 \mathrm{~dB}$ average loss, but with a single allowed diameter of the drops $D=1.9 \mathrm{~mm}$ to evaluate the possible influence of more homogeneously drop sizes on the standard deviation. Results of such simulations are presented in Fig. 4. As one can see from the (a) part, now the histogram is split into several columns corresponding to the events with 0-6 drops. The calculated standard deviation in the case of one single experiment is slightly smaller in comparison with that in Fig. 3(a). On the other hand, the average
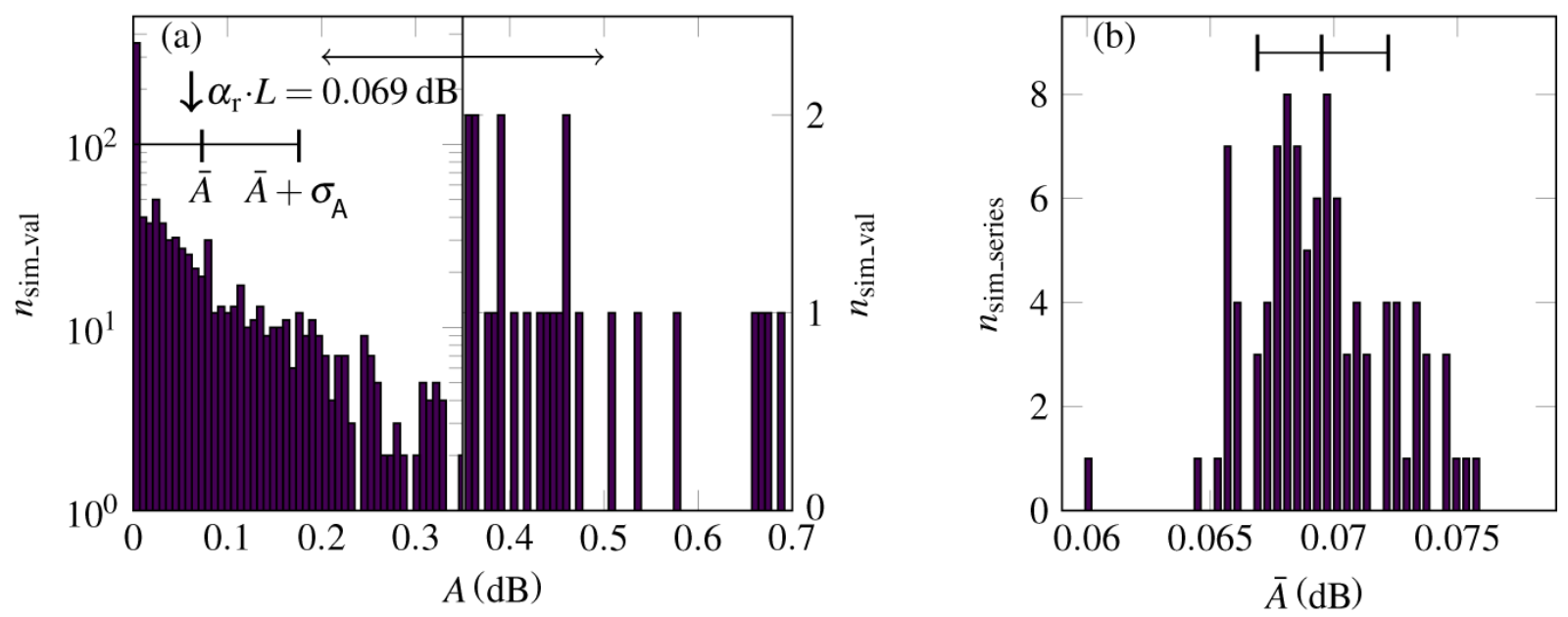

Fig. 3. (a) Distribution of 1000 simulated absorbance $A$ values at $R=40 \mathrm{~mm} / \mathrm{h}$ rain rate, $f=0.3 \mathrm{THz}$ frequency and Weibull distribution of drop sizes. The graph is split in the middle to reveal better lower numbers of $n_{\text {sim_val }}$ with high absorbances. The bar width equals $0.007 \mathrm{~dB}$. (b) Distribution of the average values of $A$, obtained in simulated 100 absorbance data set series by averaging 1000 absorbance values within each set. Similarly to (a), a central vertical line indicates the obtained average, and two other lines show a standard deviation from the average for such series $\left( \pm \sigma_{\bar{A}}\right)$. 

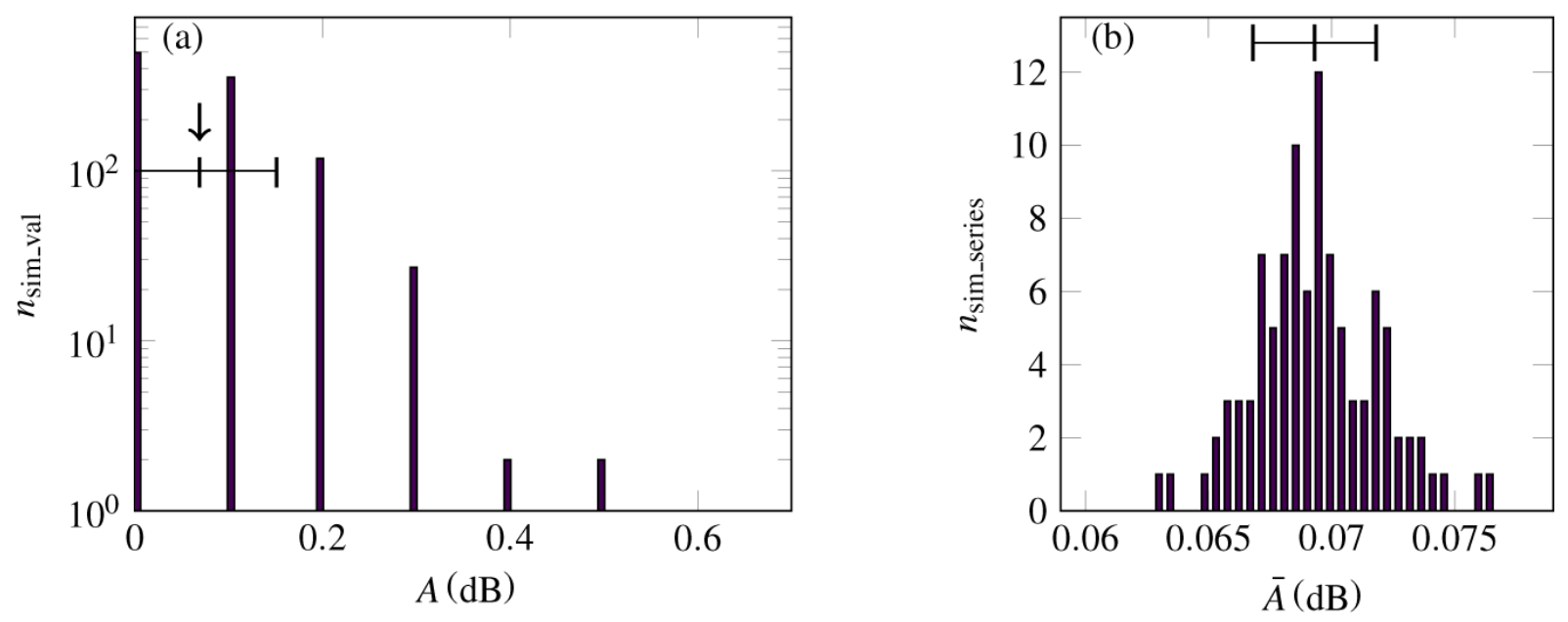

Fig. 4. (a) Distribution of 1000 simulated absorbance values at $f=0.3 \mathrm{THz}$ frequency with the $0.069 \mathrm{~dB}$ average and Poisson probability distribution of drops with a single $1.9 \mathrm{~mm}$ diameter. (b) Distribution of the average values of $A$, obtained in the simulated 100 absorbance data sets of 1000 values. Vertical lines indicate the averages and standard deviations in the same way like in Fig. 3.

value for 100 experiment series and its standard deviation in Fig. 4(b) are very close to the one obtained in Fig. 3(a), confirming that larger series of substantially more than 1000 measurements would probably lead to very similar statistical results despite size restrictions.

The same average loss was selected as a basis for comparison between the Weibull distribution function approximation of the real rain and the single drop size approximation for the laboratory-controlled rain. An equal rain rate though would be a worse option, since the interplay be- tween low velocities of raindrops in the case of laboratory conditions, different size distributions in comparison with the real rain inevitably lead to average absorbance differences for the same rain rates. The $R=40 \mathrm{~mm} / \mathrm{h}$ rain rate would lead to an approximately $0.23 \mathrm{~dB}$ average loss based on the linear fit presented in Fig. 5 of [20] instead of $0.069 \mathrm{~dB}$. In addition, most data points in this reference are given for an extreme rain of $50-400 \mathrm{~mm} / \mathrm{h}$, leading to a more than one order of magnitude larger absorbance in the middle of the range.
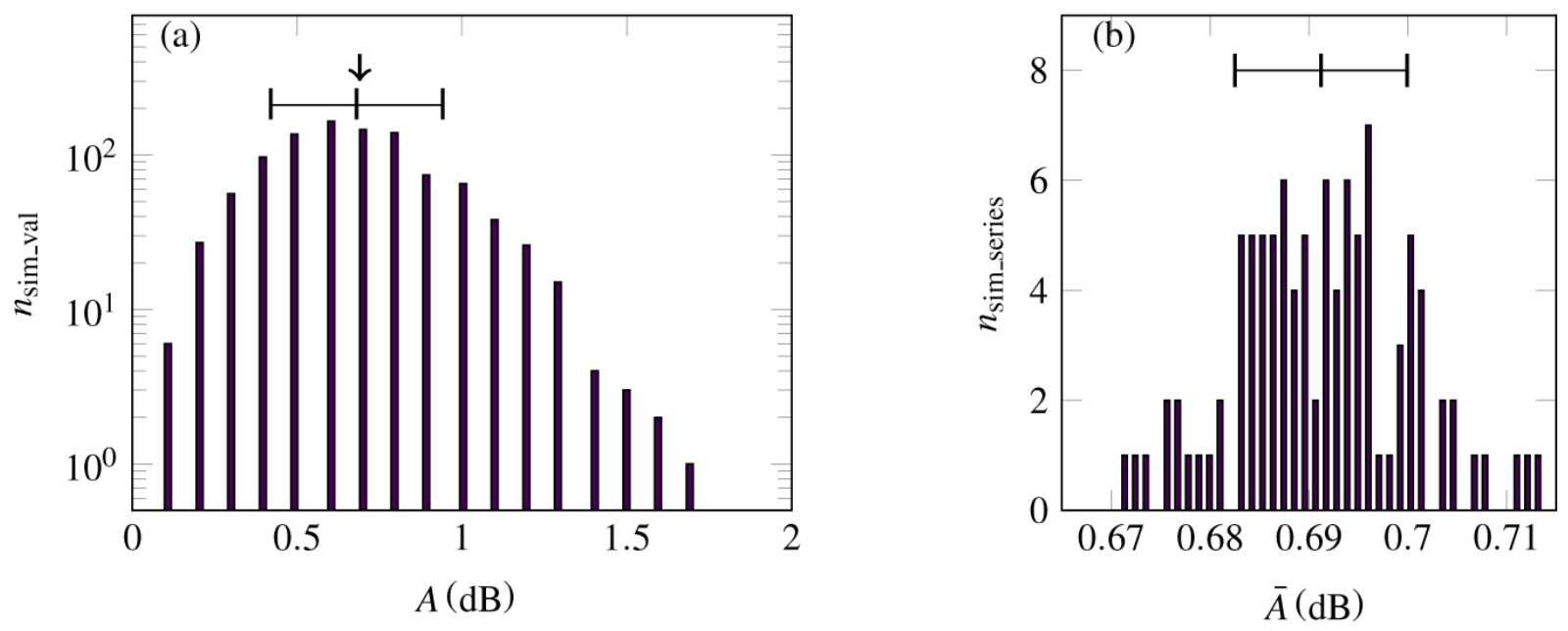

Fig. 5. (a) Distribution of 1000 simulated absorbance values with the $0.69 \mathrm{~dB}$ average and Poisson probability distribution of drops with a single $1.9 \mathrm{~mm}$ diameter at $f=0.3 \mathrm{THz}$ frequency. (b) Distribution of the average values of $A$, obtained by generating 100 data sets and averaging values in each set. Vertical lines indicate the averages and standard deviations in the same way like in Figs. 3 and 4. 
An additional series of experiments was performed with a ten times larger average absorbance of $0.69 \mathrm{~dB}$, corresponding to the case of extreme rain. Results of these simulations are presented in Fig. 5. As one can clearly see in the (a) panel of the figure, dispersion is greatly reduced (when normalized to the average value), as expected when the average number of interacting raindrops increases. Also, all averaged absorbance values for 100 experiment series fit into the $\pm 4 \%$ range. However, deviations in the order of tens of percents were observed experimentally [20], thus suggesting that there were additional reasons for the absorbance dispersion during the experiments in addition to the raindrop statistics considered in this paper. These differences, in fact, are much larger than the calculated ones between Figs. 3 and 4 . Thus, it might be concluded that laboratory-based experiments could be a valuable tool for estimating (and even overestimating) the upper limit of rain induced noise in communication channels despite of raindrop size distribution differences.

\section{Conclusions}

Absorbance uncertainties due to the discrete nature of rain were evaluated for two communication scenarios employing highly directional terahertz beams and an extreme densification of the infrastructure. It was demonstrated by numerical simulations that deviations might be comparable with the average value of the absorbance once the total beam-rain interaction volume is reduced to $V \approx 1 \mathrm{~m}^{3}$, as might be expected in the so-called $5 \mathrm{G}$ networks and beyond. Deviations might exceed the average value by an order of magnitude in the case of heavy rain when estimated for a narrow beam with a few centimetres diameter in several metres from the laboratory-based setup described in [20]. Nevertheless, the numerically simulated deviations for the extreme rain are much smaller than the experimentally observed ones. Thus, a new application of laboratory-based rain attenuation experiments could be envisaged - they can be a valuable tool for estimating the upper limit of rain induced noise in $\mathrm{THz}$ communication channels.

\section{Acknowledgements}

This work was supported by the Research Council of Lithuania (Project LAT 04/2016).

\section{References}

[1] Ericsson. Traffic Exploration Tool (2017), https:// www.ericsson.com/TET/trafficView/loadBasicEditor.ericsson

[2] C.E. Shannon, Communication in the presence of noise, Proc. IRE 37(1), 10 (1949), https://doi. org/10.1109/JRPROC.1949.232969

[3] M. Koch, in: Terahertz Frequency Detection and Identification of Materials and Objects, eds. R.E. Miles, X.C. Zhang, H. Eisele, and A. Krotkus (Springer Netherlands, Dordrecht, 2007) pp. 325338.

[4] J. Federici and L. Moeller, Review of terahertz and subterahertz wireless communications, J. Appl. Phys. 107(11), 111101 (2010), https://doi. org/10.1063/1.3386413

[5] H.J. Song and T. Nagatsuma, Present and future of terahertz communications, IEEE Trans. Terahertz Sci. Technol. 1(1), 256 (2011), https:// doi.org/10.1109/TTHZ.2011.2159552

[6] I.F. Akyildiz, J.M. Jornet, and C. Han, Terahertz band: Next frontier for wireless communications, Phys. Commun. 12(Supplement C), 16 (2014), https://doi.org/10.1016/j.phycom.2014.01.006

[7] T. Kürner and S. Priebe, Towards THz communications - status in research, standardization and regulation, J. Infrared Millim. Terahertz Waves 35(1), 53 (2014), https://doi.org/10.1007/s10762013-0014-3

[8] T. Nagatsuma, G. Ducournau, and C.C. Renaud, Advances in terahertz communications accelerated by photonics, Nat. Photonics 10(6), 371 (2016), https://doi.org/10.1038/nphoton.2016.65

[9] D.M. Pozar, Microwave Engineering (John Wiley \& Sons, New York, 2012).

[10]S. Han, C.-1. I, Z. Xu, and C. Rowell, Large-scale antenna systems with hybrid analog and digital beamforming for millimeter wave 5G, IEEE Commun. Mag. 53(1), 186 (2015), https://doi. org/10.1109/MCOM.2015.7010533 
[11]R.W. Heath, N. González-Prelcic, S. Rangan, W. Roh, and A.M. Sayeed, An overview of signal processing techniques for millimeter wave MIMO systems, IEEE J. Sel. Topics Signal Process. 10(3), 436 (2016), https://doi.org/10.1109 ISTSP.2016.2523924

[12]T. Nagatsuma, K. Oogimoto, Y. Inubushi, and J. Hirokawa, An overview of signal processing techniques for millimeter wave MIMO systems, Nano Commun. Netw. 10(Supplement C), 1(2016), https://doi.org/10.1016/j.nancom.2016.07.005

[13] International Telecommunication Union, Recommendation ITU-R P.676-11: Attenuation by Atmospheric Gases (09/2016), https://www.itu. int/rec/R-REC-P.676-11-201609-I

[14]International Telecommunication Union, Recommendation ITU-R P.838-3: Specific Attenuation Model for Rain for Use in Prediction Methods (03/2005), https://www.itu.int/rec/R-RECP.838-3-200503-1

[15]M. Tamošiūnaité, S. Tamošiūnas, M. Žilinskas, and M. Tamošiūniené, in: Electromagnetic Waves, ed. V. Zhurbenko (InTech, Rijeka, 2011) pp. 157-172.

[16]M. Sekine, S. Ishii, S.I. Hwang, and S. Sayama, Weibull raindrop-size distribution and its application to rain attenuation from $30 \mathrm{GHz}$ to $1000 \mathrm{GHz}$, Int. J. Infrared Millimeter Waves 28(5), 383 (2007), https://doi.org/10.1007 s10762-007-9221-0

[17]S. Ishii, M. Kinugawa, S. Wakiyama, S. Sayama, and T. Kamei, Rain attenuation in the microwaveto-terahertz waveband, Wireless Eng. Technol.
$7(02), \quad 59 \quad$ (2016), https://doi.org/10.4236/ wet.2016.72006

[18]E. Villermaux and B. Bossa, Single-drop fragmentation determines size distribution of raindrops, Nat. Phys. 5(9), 697 (2009), https://doi. org/10.1038/nphys1340

[19]E. Adirosi, L. Baldini, F. Lombardo, F. Russo, F. Napolitano, E. Volpi, and A. Tokay, Comparison of different fittings of drop spectra for rainfall retrievals, Adv. Water Resour. 83, 55 (2015), https:// doi.org/10.1016/j.advwatres.2015.05.009

[20]J. Ma, F. Vorrius, L. Lamb, L. Moeller, and J.F. Federici, Comparison of experimental and theoretical determined terahertz attenuation in controlled rain, J. Infrared Millim. Terahertz Waves 36(12), 1195 (2015), https://doi. org/10.1007/s10762-015-0200-6

[21]H.C. van de Hulst, Light Scattering by Small Particles (John Wiley \& Sons, New York, 1957).

[22]P.S. Ray, Broadband complex refractive indices of ice and water, Appl. Opt. 11(8), 1836 (1972), https://doi.org/10.1364/AO.11.001836

[23]C. Mätzler, MATLAB Functions for Mie Scattering and Absorption, Version 2, Research Report No. 2002-11 (Institute of Applied Physics, University of Bern, 2002), http://www.iap.unibe.ch/publications/pub-detail.php?lang=en $\mid \& i d=199$

[24]S.F. Yunas, M. Valkama, and J. Niemelä, Spectral and energy efficiency of ultra-dense networks under different deployment strategies, IEEE Commun. Mag. 53(1), 90 (2015), https://doi. org/10.1109/MCOM.2015.7010521 


\title{
5G / B5G BEVIELIS RYŠYS: TERAHERCINIŲ BANGŲ SILPNINIMO DE்L LIETAUS NEAPIBRËŽTUMAI
}

\author{
M. Tamošiūnaitè ${ }^{a}, \mathrm{~V}$. Tamošiūnas ${ }^{\mathrm{a}, \mathrm{b}}, \mathrm{G}$. Valušis ${ }^{\mathrm{a}}$ \\ ${ }^{a}$ VMTI Fiziniu ir technologijos mokslu centras, Vilnius, Lietuva \\ ${ }^{\mathrm{b}}$ Vilniaus universitetas, Vilnius, Lietuva
}

\begin{abstract}
Santrauka
Šiame darbe pritaikant statistinius metodus nagrinëjami terahercinių $(\mathrm{THz})$ bangų silpninimo ypatumai stipraus lietaus sąlygomis. Modeliuojant buvo atsižvelgta i pagrindinius 5-os kartos (5G / B5G) bevielių tinklų veikimo principus: infrastruktūros tankèjimą ir signalo sklidimo kryptingumą. Skaičiavimai atlikti remiantis literatūroje aprašytais faktinio ir laboratorijoje kontroliuojamo lietaus lašų dydžio pasiskirstymais. Modeliavimo rezultatai parode, kad THz bangai ir lietaus lašams sąveikaujant $100 \mathrm{~m}^{3}$ tūryje pasireikštų daugiau kaip $1 \%$ sugerties svyravimai. Laboratorijoje kontroliuojamo lietaus atveju, esant trumpiems atstumams ir siauram spinduliui, šie svyravimai gali viršyti vidutinę sugerties vertę eile. Mo-
\end{abstract}

deliavimo rezultatu palyginimas fiksuotos vidutinès sugerties atveju atskleidè, kad eksperimentuose su vienodo dydžio lašais yra tikètini šiek tiek mažesni sugerties koeficiento nuokrypiai, palyginti su tikru lietumi, aprašomu Weibullo funkcijos pasiskirstymu. Nepaisant to, abiem atvejais prognozuojami svyravimai buvo gerokai mažesni, nei buvo stebimi anksčiau skelbtuose eksperimentu rezultatuose. Tai patvirtina tokių eksperimentų taikymo galimybę. Kadangi dauguma pramonèje naudojamos irangos nèra suprojektuota atlikti kalibruotus 5G / B5G belaidžių tinklų matavimus bangai sklindant oru, tokie eksperimentai gali būti naudojami siekiant prognozuoti tikètiną duomenų perdavimo našumą. 